concepts, this classical approach may appear to be somewhat outmoded, but is not entirely unjustified if the main concern is with structure and function and if, as in the present case, thermodynamic aspects are dealt with in a later chapter. It is a pity, nevertheless, that so much space is occupied with attempts to calculate xylem conductivities from sap velocities obtained by the thermoelectric method; attractive though this method may be, the results cannot be accepted so uncritically. The account of phloem transport includes much of the author's well known research, and even though biased in favour of mass flow, it provides a well reasoned summary of the problem. To introduce some measure of impartiality, however, a short summary prepared by D. S. Fensom of his microfibrillar flow theory is included.

For those who are able to follow the rather complex arguments, the chapter by Dr Tyree on the steady state thermodynamics of translocation in plants is something of an unexpected bonus. $\mathrm{He}$ describes how the appropriate Onsager transport equations are derived, how they can be applied to interpret electroosmosis and streaming potentials, and how, on the basis of energy dissipation, they can be used to evaluate the relative importance of electrical and pressure gradients in xylem and phloem transport.

The final chapter by Zimmerman on storage, mobilization and the circulation of assimilates is reasonably straightforward and returns the reader once again to the familiar world of classical plant physiology.

Though perhaps somewhat less original in its approach than might have been expected from its stated aims, the book as a whole differs sufficiently from previous publications in this field to merit serious attention. Many of the topics have been dealt with rather superficially, and several important aspects of structure-function relations have been omitted, but at least the authors have been reasonably successful in producing some readable accounts from a mass of factual, and frequently confusing, observations. L. LEYTON

\section{Keeping Books}

Advances in Librarianship. Edited by Melvin J. Voigt. Vol. 2. Pp. xi +377. (Seminar Press: New York and London, 1971.) n.p.

THERE are a variety of Annuals in most fields, librarianship being no exception; until recently, however, because this has been a fairly sterile discipline, several new Annuals have appeared concurrently with the "break-out" mainly into library automation.
Advances in Librarianship has now completed its second cycle, the series purporting to cover "the field of library science in its broadest aspects ... providing critical articles and surveys of specific aspects of the subject based on the published literature, research in progress, and developments in libraries of all types". The blurb goes on to clajm that the "depth of coverage results in surveys of advances in the field that will be permanently useful in orienting librarians and students". This is, of course, difficult, for in any Annual cycle the probability that a subject has reached maturity within that cycle is low. Topicality and permanence are not good bedfellows and the current volume of Advances illustrates this as well as most other Annuals.

One fairly uniform shortcoming of the nine sections which comprise this volume is the concentration on North American experience. For example, in the first section, Budington ("Access to Information") acknowledges the rest of the world by a passing reference to a three page British review, published in 1965. This is a pity for, although historical and descriptive reviews are of limited value in themselves, the effect of different requirements and economic circumstances on a problem can cause both objectives, methods and results to be markedly different.

In contrast, however, Bishop ("Information in Medicine") covers his subject as uniformly as the published literature permits.

Bosseau ("The Computer in Serials Processing and Control"), although treating the "rest of the world" in a somewhat cavalier fashion, provides detailed descriptions of some generalized systems, although one wonders whether such detail is appropriate in this volume. In contrast, Veaner ("Micropublication") covers his subject, if anything, too compactly.

Beasley ("The Changing Role of the State Library"), in a section of interest only perhaps to American readers, observes that the role of State Libraries is changing and will continue to change, and concludes that, because they change, they are more innovative than other libraries. Monroe ("Reader Services to the Disadvantaged in Inner Cities") is also probably only of interest to American readers, whereas in contrast Schrader ("Armageddon in International Copyright: Review of the Berne Convention, the Universal Convention, and the Present Crisis in International Copyright"), while concerned predominantly with the American viewpoint, provides an extremely lucid and attractively written exposition of her subject.

There is also a section by Starr ("Oral History: Problems and Prospects").

On working through this volume, one is left with the feeling that a number of interesting topics had been covered without much uniformity of presentation or level. One is left with a vague unease as to whether all the subjects covered are in fact ripe for review. It is also difficult to envisage a reader who would be equally interested in all the sections. This volume is certainly ideal reading for any librarian wishing to familiarize himself with sufficient background and jargon before attending an interview for a library post in North America.

N. S. M. Cox

\section{Kinetic Isotope Effects}

Isotope Effects in Chemical Reactions. Edited by Clair J. Collins and Newell S. Bowman. Pp. xi+435. (Van Nostrand Reinhold: London, August 1971.) $£ 11.25$.

THE effect of isotopic substitution on the rates of chemical reactions was first observed and qualitatively explained in terms of zero-point energy soon after the discovery of deuterium in the early 1930s. The modern treatment of the subject by Bigeleisen and by Melander around 1950, and subsequent developments, retain much of this early idea.

The measurement of kinetic isotope effects, at first with deuterium and later with heavier isotopes, has become a powerful method in the investigation of reaction mechanisms. Early work was exclusively concerned with effects of deuterium substitution at a bond which is expected to be broken in the ratelimiting step. The rate changes are large in this case and their presence or absence identifies the rate-controlling process.

More recent applications have emphasized the information provided by the actual magnitude of the effects. Advances in experimental technique have also made the measurement of secondary hydrogen isotope effects easier. The mechanistic interpretation of these more quantitative results requires a more sophisticated theoretical analysis, which has become feasible with the development (chiefly by Wolfsberg and Stern) of computational techniques based on Bigeleisen's theory. The book under review contains five essays on this topic, and it could aptly be subtitled "Variations on a Theme by Bigeleisen". The distinguished authors give an introductory account of the theory (Van Hook), a more specialized and more personal treatment of the same topic (Thornton and Thornton), a discussion of kinetic secondary deuterium isotope effects in aliphatic nucleophilic substitution (Shiner), a treatment of the same topic from the point of view of a different laboratory (Sunko and Borčic), and a survey of kinetic heavy-atom isotope effects (Fry). 